\title{
Effect of raloxifene on salivary sex steroid concentrations in premenopausal women
}

\author{
Robert T Chatterton Jr ${ }^{1,3}$, JoAnne Zujewski ${ }^{2}$, Esnar T Mateo ${ }^{1,3}$, Jennifer Eng-Wong ${ }^{2}$ and V Craig Jordan ${ }^{3,4}$ \\ ${ }^{1}$ Department of Obstetrics and Gynecology, Feinberg School of Medicine, Northwestern University, Chicago, Illinois 60611, USA \\ ${ }^{2}$ Center for Cancer Research, National Cancer Institute, Bethesda, Maryland, USA \\ ${ }^{3}$ The Robert H. Lurie Comprehensive Cancer Center, Feinberg School of Medicine, Northwestern University, Chicago, Illinois 60611, USA \\ ${ }^{4}$ Fox Chase Cancer Center, 333 Cottman Avenue, Philadelphia, Pennsylvania 19111, USA \\ (Requests for offprints should be addressed to V C Jordan at Fox Chase Cancer Center; Email: V.Craig.Jordan@fccc.edu)
}

\begin{abstract}
Raloxifene is a selective oestrogen receptor modulator used clinically for the treatment and the prevention of osteoporosis in postmenopausal women. The drug has been evaluated in the Study of Tamoxifen and Raloxifene as an agent to reduce breast cancer incidence in postmenopausal women at high risk. However, about 30\% of women who develop breast cancer do so in their premenopausal years. In this pilot study, salivary oestradiol and progesterone were determined throughout the menstrual cycle for a total of 22 subjects, 14 of whom completed pre- and postraloxifene (60 mg daily) salivary collections. The mean concentration of oestradiol

during the menstrual cycle when subjects were taking raloxifene was significantly greater $(P<0 \cdot 001)$ than during baseline cycles. Neither salivary progesterone and cortisol nor menstrual cycle length were affected by raloxifene treatment. These data demonstrate that raloxifene administered to premenopausal women increases the concentration of oestradiol that diffuses into the salivary glands, and which presumably represents the concentration available to other organs as well. The results reflect increases in serum oestradiol reported earlier.

Journal of Endocrinology (2006) 191, 599-604
\end{abstract}

\section{Introduction}

Raloxifene is a selective oestrogen receptor modulator (SERM) that is used for the treatment and the prevention of osteoporosis (Jordan et al. 2001). SERMs are nonsteroidal compounds that interact with the oestrogen receptor (ER) signal transduction pathway, in different target tissues, to induce either oestrogen-like or antioestrogenic effects (Jordan 2001). Raloxifene reduces the incidence of carcinogeninduced rat mammary tumours (antioestrogenic) (Gottardis \& Jordan 1987) but lowers circulating cholesterol and maintains bone density in ovariectomized rats (oestrogenic) (Jordan et al. 1987a, Black et al. 1994). Raloxifene, originally referred to in the literature as LY156758, was noted to be less uterotrophic in the rodent uterus than tamoxifen (Black et al. 1983). Overall, these data encouraged the clinical testing of raloxifene as a potential preventive for osteoporosis with the beneficial side effects of lowering circulating cholesterol, and reducing the incidence of breast cancer without an increase in the incidence of endometrial cancer. The related SERM, tamoxifen, has been associated with a small but significant increase in the risk of endometrial cancer in postmenopausal women (Fisher et al. 1998). Raloxifene effectively increases bone density, decreases breast cancer incidence and does not increase endometrial cancer incidence in osteoporotic postmenopausal women (Cummings et al. 1999, Ettinger et al. 1999, Cauley et al. 2001). Based on these data, raloxifene has been evaluated against tamoxifen in the Study of Tamoxifen and Raloxifene (STAR) trial but only in postmenopausal women at elevated breast cancer risk. (Vogel et al. 2006). The STAR trial demonstrated equivalent efficacy for tamoxifen and raloxifene preventing invasive breast cancer but with fewer thromboembolic events, cataracts, cataract surgeries and endometrial cancers in those women taking raloxifene.

A concern with the use of tamoxifen for reduction in breast cancer risk in premenopausal women has been its potential to cause a decrease in bone density and osteoporosis in the early postmenopausal years (Powles et al. 1996). There is no information about the long-term actions of raloxifene in the premenopausal women, so this population was excluded from the STAR trial.

In an earlier report, we used a salivary assay to monitor oestradiol and progesterone throughout the menstrual cycle (Chatterton et al. 2005). The monitoring technique is noninvasive and has the advantage of simplicity and convenience for the patient. Our aim was to evaluate the salivary assay as a potential tool for chemoprevention studies in situations where the agent could potentially affect the menstrual cycle but daily blood sampling was inappropriate. 
Salivary steroids are generally considered to represent the 'free' or 'diffusible' fraction of the plasma concentrations (Read et al. 1990, Hold et al. 1995), and, therefore represents not only the concentration that enters the salivary gland but also that available to other tissues. In contrast, the major fraction of plasma sex steroids are strongly bound to their respective binding globulins and concentrations are normally reported as the total concentration of all bound and unbound forms. In the present study, we report the actions of raloxifene on changes in salivary levels of oestradiol and progesterone in premenopausal women at high risk for breast cancer, who participated in an evaluation of the effects of raloxifene on bone density (Eng-Wong et al. 2006).

\section{Materials and Methods}

\section{Subjects}

Subjects were recruited at the National Cancer Institute, Bethesda Maryland, in a phase 2 clinical trial designed to study the safety and tolerability of raloxifene in premenopausal women at high risk of developing breast cancer (Eng-Wong et al. 2006). Between 1998 and 2002, 30 women were enrolled and started treatment with raloxifene. Out of the 22 subjects who collected saliva, 14 completed collections at baseline after 3-12 months of raloxifene. Five did not complete the raloxifene portion of the study and three did not have a baseline. For the women who signed the consent for the saliva study, the age range was 40-47 years, the median age was $44 \cdot 5$ and the mean age was $43 \cdot 9$. The average body mass index (BMI) was $24 \cdot 5$.

Eligible subjects included women between the ages of 23 and 47 with an increased risk of breast cancer by at least one of the following factors. Gail model risk assessment $\geq 1 \cdot 7 \%$ at 5 years, (Gail et al. 1989) a family history consistent with hereditary breast cancer, (Shattuck-Eidens et al. 1997) a diagnosis of lobular carcinoma in situ, atypical ductal hyperplasia or locally treated ductal carcinoma in situ. Subjects were required to have had regular menstrual cycles (defined as 26-35 days) for the 6 months preceding enrolment in the trial. Premenopausal status was additionally verified by a follicle stimulating hormone level $<20 \mathrm{mIU} / \mathrm{ml}$. Subjects could not have had steroid therapy or oral contraceptives within 6 months prior to study entry. Also excluded were women with infertility of ovarian etiology or recurrent ovarian cysts, or pulmonary embolism, deep venous thrombosis, any bleeding disorder or liver cirrhosis.

Subjects received a $60 \mathrm{mg}$ dose of raloxifene (and calcium carbonate $1250 \mathrm{mg}$ ) daily for up to 24 months. Saliva was collected daily for 1 month after 3-12 months on raloxifene. Bone mineral density was a primary end point and has been reported elsewhere (Eng-Wong et al. 2006). Hormone levels were among the secondary objectives of the study. Circulating prolactin and oestradiol levels taken at a single sampling time in the menstrual cycle are reported elsewhere (Faupel-Badger et al. 2006).

Saliva was collected daily between 0700 and $0900 \mathrm{~h}$ in $8 \mathrm{ml}$ vials containing $0.5 \mathrm{mg} \mathrm{NaN}$ as a preservative beginning on the first day of the menstrual cycle and continuing until the last day. Salivary secretions were stimulated by chewing a half stick of sugarless gum; the subjects spat into the vial until it was at least half full. The vials were then sealed with a stopper that was provided, the saliva was mixed with the dried preservative, and the subject number and date were written on the vial. The vials were stored at room temperature until the menstrual cycle had been completed. After completion of the cycle, the samples were brought to the clinic for shipment to the laboratory at the Robert $\mathrm{H}$ Lurie Comprehensive Cancer Center, Northwestern University, Chicago, IL, USA.

All procedures were approved by the NIH and Northwestern University Institutional Review Boards and written informed consent was obtained.

\section{Laboratory procedures}

After receipt in the laboratory, the samples were frozen until they were assayed. The procedures for measurement of salivary progesterone, oestradiol and cortisol have been validated and described in detail previously (Chatterton et al. 1996, 1997, Lu et al. 1997, 1999). Briefly, the samples were thawed and centrifuged at $2500 \mathrm{~g}$ for $30 \mathrm{~min}$. The precipitate was discarded and the supernatant was used for the assays. All the three steroids were measured by radioimmunoassays. Progesterone and cortisol assays utilized tritiated tracers and oestradiol assays were performed with ${ }^{125}$ I-oestradiol. Antisera for progesterone and cortisol were produced and evaluated as described previously (Cheesman \& Chatterton 1982). Antiserum and tracer for the oestradiol assay were obtained from Diagnostic Systems Laboratories (Webster, TX, USA). The intra- and interassay coefficients of variation (CV)s were 13.8 and $5 \cdot 1 \%$ for progesterone, $16 \cdot 1$ and $15 \cdot 6 \%$ for oestradiol, and $13 \cdot 6$ and $6 \cdot 7 \%$ for cortisol respectively. Lower interassay than intraassay $\mathrm{CVs}$ are the result of numerous samples that were at or below the limit of detection of the assays, while quality controls that were run with each assay for determination of precision were well within the range of the respective assays. The quality control preparations from which the interassay CVs were determined were a pool of saliva that had been stripped of steroids by incubation with agarose-coated charcoal and to which $200 \mathrm{pg} / \mathrm{ml}$ of progesterone, $12 \mathrm{pg} / \mathrm{ml}$ of oestradiol and $5.0 \mathrm{ng} / \mathrm{ml}$ of cortisol had been added. The steroid assays have been tested for stability at room temperature in the presence of $\mathrm{NaN}_{3}$ and found to be stable for 3 months. No significant differences in assayed values were found.

\section{Statistical analysis}

The mean and standard error for all subjects in a particular group were calculated for each day of the menstrual cycle. The last day 
of the menstrual cycle (the day before menstrual bleeding) was designated cycle-day 0 . Saliva samples from day -28 through the end of the cycle were assayed for oestradiol. Those from days -17 to 0 were assayed for progesterone. The criteria used to determine the day of ovulation were: (1) progesterone values of $>60 \mathrm{pg} / \mathrm{ml}$ or more on 3 or more days in a 4-day period occurring within days -4 to -10 from the end of the cycle; (2) cycle length of $>24$ days; and (3) oestradiol values of $<$ $12 \mathrm{pg} / \mathrm{ml}$ during the first 10 days of the cycle. With these criteria met, the day of ovulation was determined by counting back 13 days from the last day of the cycle. Usually, there was a peak of oestradiol within \pm 2 days from day -13 . If so, we chose the day after the peak as the day of ovulation as validated by others (Ellison 1988). For purposes of displaying the data, the cycle was renumbered with the day of ovulation assigned as 'day 0.' The follicular phase was numbered negatively and the luteal phase positively from the day of ovulation (day 0 was included with the follicular phase for this comparison) (Chatterton et al. 2005). The data were evaluated by the box plot procedure (SYSTAT Software, Inc., Richmond, CA, USA) and 5 out of 494 progesterone values that were greater than 3 S.D. from the mean were deleted from the group receiving raloxifene. No other outliers were found.

The significance of daily differences between baseline values and those during raloxifene treatment was determined by paired Student's $t$-test.

\section{Results}

Salivary progesterone, oestradiol and cortisol data were evaluated in complete menstrual cycles before raloxifene treatment began and again during treatment. The mean data for baseline and raloxifene cycles are shown in Table 1. The mean concentration of oestradiol during menstrual cycles in which raloxifene was given was significantly $(P<0 \cdot 0001)$ greater than in baseline cycles. Progesterone and cortisol concentrations were not affected by administration of $60 \mathrm{mg}$ raloxifene per day. No differences were noted for data collected at 3 or 12 months during raloxifene treatment so data were pooled.
The pattern of daily oestradiol concentrations throughout the baseline and treatment cycles is shown in Fig. 1. It is clear that an elevation in oestradiol occurred throughout the entire cycle and was not confined to the follicular or luteal phases. The preovulatory peak was increased proportionately. The pattern of progesterone concentrations in baseline cycles and during raloxifene treatment is shown in Fig. 2. It is evident that progesterone was unaffected by the treatment. The levels of progesterone were similar across all days of the cycle beginning on day -4 , the first day that progesterone was measured. Cortisol was measured on 4 days of each menstrual cycle (two follicular phase and two luteal phase days). No difference in levels was observed at any of the random time points in which samples were assayed (Table 1).

Cycle length in baseline and raloxifene treatment cycles was recorded. Baseline cycle length was $24 \cdot 4 \pm 3 \cdot 8$ (S.D.) days and averaged $25 \cdot 0 \pm 3 \cdot 4$ (S.D.) days $(P=0 \cdot 60)$ during raloxifene treatment (first cycles only). Of subjects with two cycles during raloxifene treatment, the first and second cycles averaged $25 \cdot 8 \pm 2 \cdot 6$ (S.D.) and $27 \cdot 0 \pm 2 \cdot 2$ (S.D.) days respectively $(P=$ $0 \cdot 29)$. Thus, raloxifene affected oestradiol levels without affecting cycle length regardless of duration of treatment.

\section{Discussion}

The principal reason for the evaluation of raloxifene in premenopausal women was to investigate the possible application of this SERM as an alternative to tamoxifen in women with active menstrual cycles. Approximately one-third of all women who develop breast cancer do so in their premenopausal years. At present, tamoxifen is available for the reduction of breast cancer risk in both pre- and postmenopausal women but there are presently no long-term data on the actions of raloxifene on the reproductive physiology of premenopausal women.

In a previous study, the effect of 100 and $200 \mathrm{mg}$ daily doses of raloxifene administered for up to 28 days on serum oestradiol, progesterone, cortisol and gonadotrophins was determined in healthy premenopausal women (Baker et al. 1998). The area under the curve of oestradiol for the entire menstrual cycle was $25 \%$ higher than the baseline cycles with the daily $100 \mathrm{mg}$ dose

Table 1 Mean salivary steroid hormone concentrations for baseline and raloxifene treatment menstrual cycles

\begin{tabular}{|c|c|c|c|c|}
\hline & No. daily measurements & Range & Mean & S.E.M. $( \pm)$ \\
\hline \multicolumn{5}{|l|}{ Analyte } \\
\hline \multicolumn{5}{|l|}{ Oestradiol (pg/ml) } \\
\hline Baseline & 379 & $0-49 \cdot 8$ & $5 \cdot 91$ & $0 \cdot 37$ \\
\hline During raloxifene & 680 & $0-118 \cdot 3$ & $10 \cdot 93$ & $0 \cdot 52$ \\
\hline \multicolumn{5}{|c|}{ Progesterone $(\mathrm{pg} / \mathrm{ml})$} \\
\hline Baseline & 282 & $0-401 \cdot 8$ & $119 \cdot 7$ & $4 \cdot 6$ \\
\hline During raloxifene & 502 & $0-393 \cdot 0$ & $111 \cdot 1$ & $3 \cdot 2$ \\
\hline \multicolumn{5}{|l|}{ Cortisol (ng/ml) } \\
\hline Baseline & 62 & $0 \cdot 5-10 \cdot 5$ & $3 \cdot 69$ & $0 \cdot 29$ \\
\hline During raloxifene & 103 & $0 \cdot 5-10 \cdot 3$ & $3 \cdot 58$ & $0 \cdot 22$ \\
\hline
\end{tabular}




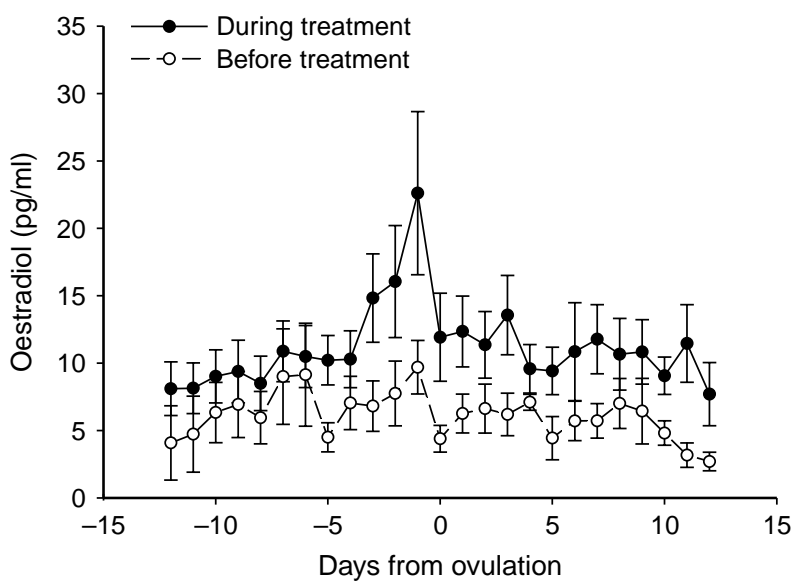

Figure 1 Pattern of mean \pm S.E.M. salivary oestradiol in complete menstrual cycles of 17 women at high risk for breast cancer. A comparison between baseline menstrual cycles and those during raloxifene treatment is shown.

and $43 \%$ higher with the $200 \mathrm{mg}$ dose $(P<0 \cdot 056)$. FaupelBadger et al. (2006) have recently evaluated changes in total circulating oestradiol, sex hormone binding globulin (SHBG) and prolactin in the same National Institutes of Health sponsored clinical trial of raloxifene as reported herein. The mean baseline level of serum oestradiol was $87 \pm 50$ (s.D.) $\mathrm{pg} / \mathrm{ml}$, which increased to $129 \pm 100$ (S.D.) after raloxifene treatment. To measure the effects of the elevated oestradiol on biological end points, serum SHBG and prolactin were also measured. SHBG rose from $59 \cdot 6 \pm 28 \cdot 9$ (S.D.) to $65 \cdot 6 \pm 32 \cdot 0$ (s.D.) $\mathrm{ng} / \mathrm{ml}$ after raloxifene treatment. In contrast, prolactin levels were unaffected by the increased circulating oestradiol, which suggests that raloxifene may antagonize the effect of oestrogen on prolactin secretion. This antagonism of the oestradiol response to raloxifene has been demonstrated in vitro as well (Lieberman et al. 1983).

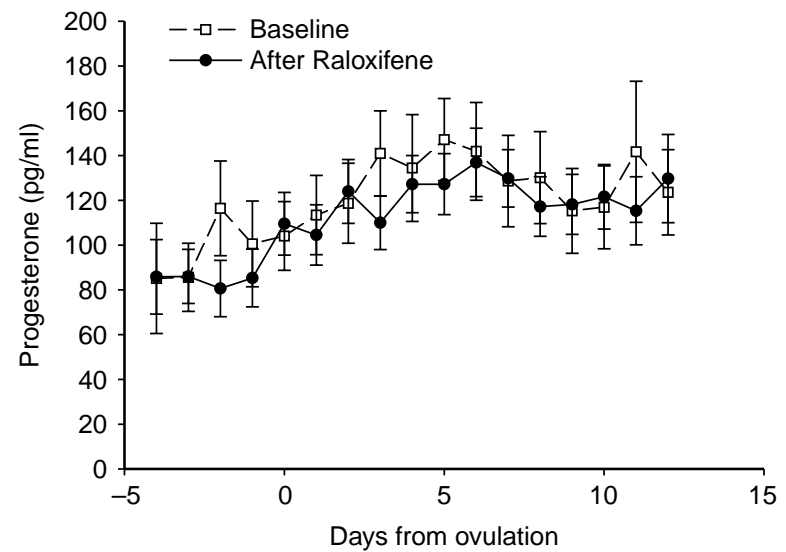

Figure 2 Pattern of mean \pm S.E.M. salivary progesterone in late follicular and complete luteal phases of menstrual cycles of 17 women at high risk for breast cancer. A comparison between baseline menstrual cycles and those during raloxifene treatment is shown.
The related SERM tamoxifen has also been shown to elevate serum oestradiol levels throughout the menstrual cycle (Groom \& Griffiths 1976, Jordan et al. 1991). The sustained use of a potential chemopreventive agent that causes an increase in oestradiol, a known promoter of breast carcinogenesis, is of particular interest. We have extensive previous experience in monitoring the changing serum levels of oestradiol or total oestrogen (oestradiol and oestrone) in premenopausal women during adjuvant treatment of breast cancer (Jordan et al. 1987b, 1991, Ravdin et al. 1988). The changes in circulating oestradiol or total oestrogen are extremely variable on a patient-to-patient basis, but elevations in oestrogen during the follicular phases are clearly more dramatic than those observed in the luteal phase. However, most of our patients received chemotherapy prior to taking long-term tamoxifen treatment (Jordan et al. 1987b, Ravdin et al. 1988). In contrast, the extended use of tamoxifen alone (4-72 months) caused an elevation of oestradiol throughout the menstrual cycle (Jordan et al. 1991).

In the present study, we assessed the concentration of oestradiol and progesterone in saliva. It is a well-accepted concept that salivary steroid hormone levels represent the free or binding globulin-unbound form of the serum concentration (Read et al. 1990, Hold et al. 1995) and, thus the concentration of the steroids in saliva represent to a greater degree the available concentration to the tissues than do serum levels. Perhaps referring to the salivary concentration as the 'free component' may not be sufficiently precise because it is argued that the fraction of plasma steroids that is bound to albumin is also available to diffuse across plasma membranes (Partridge 1981).

We observed an $85 \%$ increase in salivary oestradiol uniformly across the entire menstrual cycle with the daily $60 \mathrm{mg}$ dose. No significant effect on menstrual cycle length was observed in this or the earlier studies of raloxifene despite widely different doses, nor was there any significant effect on progesterone or cortisol concentrations.

Because of evidence from studies of tamoxifen, we conclude that raloxifene similarly increases serum and salivary oestradiol levels by increasing ovarian aromatase activity. Tamoxifen does not increase serum oestradiol in postmenopausal women (Ellmen et al. 2003) and does not increase serum gonadotrophin levels (Ellmen et al. 2003). It apparently promotes the transcription of aromatase at the proximal ovary-specific promoter (PII) promoter, which is limited to the ovary and is not active in adipose tissue (Sebastian \& Bulun 2001).

An increase in the free component of circulating oestradiol raises the question of whether raloxifene would be an efficient antitumour agent in premenopausal women. Potentially, the elevation in oestradiol could compete with raloxifene for the ER. Unfortunately, benzothiophene types of SERMs are extremely short-acting (Jordan \& Gosden 1983) and therefore do not have the ability to block completely oestrogen target tissues such as the breast (Jordan 1983). This may be the reason for the poor effectiveness of raloxifene as a breast cancer treatment in ER-positive breast cancers (Gradishar 
et al. 2000) as there is only $2 \%$ bioavailability after oral doses of raloxifene (Snyder et al. 2000). In contrast, tamoxifen has $40 \%$ bioavailability and has a long biological half-life that results in the drug being present weeks after the cessation of therapy.

The mean salivary progesterone rise after presumptive ovulation was blunted relative to previous studies from this laboratory (Lu et al. 1997, 1999) in both baseline and treatment cycles. The increase in progesterone from follicular to luteal phase has previously been shown to be less than the increase in serum progesterone (Evans 1986). This is exaggerated in women over 40 years of age (Lipson \& Ellison 1992) and may be more related to adiposity than to age according to the recent results from our laboratory (unpublished results). The women in the present study were between 40 and 47 years of age with a mean of 43.9 years and had a mean of BMI 24.5 . This may be the reason for the relatively low rise from follicular to luteal phase. The effect of age/adiposity appears to result in a small increase in the follicular phase levels of progesterone and a decrease in the luteal phase levels. This effect has not been adequately studied, and, if it has a major effect on salivary progesterone levels, this should be investigated further.

In conclusion, we have extended our previous evaluation of the salivary steroid assay to monitor menstrual cycle changes (Chatterton et al. 2005). Our aim was to investigate the worth of the salivary steroid assay for the evaluation of a potential chemopreventive in premenopausal women. The process of steroid monitoring in saliva throughout the menstrual cycle is convenient for the patient and the method avoids the inconvenience of repeated blood drawings and visits to the clinic. The method has potential value for monitoring steroidogenesis during the evaluation of any chemopreventive in premenopausal women whether or not there are any known concerns with reproductive health.

In our study, we found that the use of raloxifene in premenopausal women resulted in an increase in circulating oestradiol. The reportedly poor pharmacokinetics for raloxifene and the increase in free oestradiol would not be anticipated to provide an optimal blockade of breast ER. Indeed, it is already known that rises in oestradiol produced by tamoxifen in premenopausal patients undermine the effectiveness of ER blockade in breast cancer, but efficacy can be improved by using a combination of a luteinizing hormone releasing hormone superagonist to produce a 'medical oophorectomy' and tamoxifen (Baum et al. 2006). Present studies in our laboratory are evaluating the changes in salivary steroids during the treatment of premenopausal women with tamoxifen.

\section{Acknowledgements}

The evaluation of salivary steroids was supported by R21 CA87319 (V C J) and Specialized Program of Research Excellence (SPORE) in Breast Cancer 5 P50 CA89018 $(\mathrm{V} \mathrm{C} \mathrm{J})$. The authors declare that there is no conflict of interest that would prejudice the impartiality of this scientific work.

\section{References}

Baker VL, Draper M, Paul S, Glant MD, Shifren J \& Jaffe RB 1998 Reproductive endocrine and endometrial effects of raloxifene hydrochloride, a selective estrogen receptor modulator, in women with regular menstrual cycles. Journal of Clinical Endocrinology and Metabolism 83 6-13.

Baum M, Hackshaw A, Houghton J, Rutqvist LE, Fornander T,

Nordenskjold B, Nicolucci A, Sainsbury R \& Group ZIC 2006 Adjuvant goserelin in pre-menopausal patients with early breast cancer: results from the ZIPP study. European Journal of Cancer 42 895-904.

Black LJ, Jones CD \& Falcone JF 1983 Antagonism of estrogen action with a new benzothiophene derived antiestrogen. Life Sciences 32 1031-1036.

Black LJ, Sato M, Rowley ER, Magee DE, Bekele A, Williams DC, Cullinan GJ, Bendele R, Kauffman RF, Bensch WR et al. 1994 Raloxifene (LY139481 $\mathrm{HCI}$ ) prevents bone loss and reduces serum cholesterol without causing uterine hypertrophy in ovariectomized rats. Journal of Clinical Investigation 93 63-69.

Cauley JA, Norton L, Lippman ME, Eckert S, Krueger KA, Purdie DW, Farrerons J, Karasik A, Mellstrom D, Ng KW et al. 2001 Continued breast cancer risk reduction in postmenopausal women treated with raloxifene: 4-year results from the MORE trial. Multiple outcomes of raloxifene evaluation. Breast Cancer Research and Treatment 65 125-134.

Chatterton RT, Vogelsong KM, Lu Y-C, Ellman AB \& Hudgens GA 1996 Salivary alpha amylase as a measure of endogenous adrenergic activity. Clinical Physiology 16 433-448.

Chatterton RT, Vogelsong KM, Lu Y-C \& Hudgens GA 1997 Hormonal responses to psychological stress in men preparing for skydiving. Journal of Clinical Endocrinology and Metabolism 82 2503-2509.

Chatterton R, Mateo ET, Hou N, Rademaker AF, Acharya S, Jordan VC \& Morrow M 2005 Characteristics of salivary profiles of oestradiol and progesterone in premenopausal women. Journal of Endocrinology 186 77-84.

Cheesman KL \& Chatterton RTJ 1982 Effects of antiprogesterone antiserum on serum and ovarian progesterone, gonadotropin secretion, and pregnancy in the rat. Endocrinology 111 564-571.

Cummings SR, Eckert S, Krueger KA, Grady D, Powles TJ, Cauley JA, Norton L, Nickelsen T, Bjarnason NH, Morrow M et al. 1999 The effect of raloxifene on risk of breast cancer in postmenopausal women: results from the MORE randomized trial. Multiple outcomes of raloxifene evaluation. Journal of the American Medical Association 281 2189-2197.

Ellison PT 1988 Human salivary steroids: methodological considerations and applications in physical anthropology. Yearbook of Physical Anthropology 31 115-142.

Ellmen JPH, Partanen A \& Hayes DF 2003 Estrogenic effects of toremifene and tamoxifen in postmenopausal breast cancer patients. Breast Cancer Research and Treatment $\mathbf{8 2}$.

Eng-WongJ, Reynolds JC, Venzon D, Liewehr D, Gantz S, Danforth D, Liu ET, Chow C \& Zujewski J 2006 Effect of raloxifene on bone mineral density in premenopausal women at increased risk of breast cancer. Journal of Clinical Endocrinology and Metabolism 91 3941-3946.

Ettinger B, Black DM, Mitlak BH, Knickerbocker RK, Nickelsen T, Genant HK, Christiansen C, Delmas PD, Zanchetta JR, Stakkestad J et al. 1999 Reduction of vertebral fracture risk in postmenopausal women with osteoporosis treated with raloxifene: results from a 3-year randomized clinical trial Multiple Outcomes of Raloxifene Evaluation (MORE) Investigators (see comments) (published erratum appears in JAMA 1999 Dec 8;282(22):2124). Journal of the American Medical Association 282 637-645.

Evans JJ 1986 Progesterone in saliva does not parallel unbound progesterone in plasma. Clinical Chemistry 32 542-544.

Faupel-Badger JM, Prindiville SA, Venzon D, Vonderhaar BK, Zujewski J \& Eng-Wong J 2006 Effects of raloxifene on circulating prolactin and estradiol levels in premenopausal women at high risk for developing breast cancer. Cancer Epidemiology, Biomarkers and Prevention 15 1153-1158.

Fisher B, Costantino JP, Wickerham DL, Redmond CK, Kavanah M, Cronin WM, Vogel V, Robidoux A, Dimitrov N, Atkins J et al. 1998 Tamoxifen for prevention of breast cancer: Report of the National Surgical Adjuvant Breast and Bowel Project P-1 Study. Journal of the National Cancer Institute 90 1371-1388. 
Gail MH, Brinton LA, Byar DP, Corle DK, Green SB, Schairer C \& Mulvihill JJ 1989 Projecting individualized probabilities of developing breast cancer for white females who are being examined annually. Journal of the National Cancer Institute 81 1879-1886.

Gottardis MM \& Jordan VC 1987 Antitumor actions of keoxifene and tamoxifen in the $\mathrm{N}$-nitrosomethylurea - induced rat mammary carcinoma model. Cancer Research 47 4020-4024.

Gradishar W, Glusman J, Lu Y, Vogel C, Cohen FJ \& Sledge GW Jr 2000 Effects of high dose raloxifene in selected patients with advanced breast carcinoma. Cancer 88 2047-2053.

Groom GV \& Griffiths K 1976 Effects of the antioestrogen tamoxifen on plasma levels of luteinizing hormone, follicle stimulating hormone, prolactin, oestradiol and progesterone in normal pre-menopausal women. Journal of Endocrinology 70 421-428.

Hold KM, Douwe de Boer BS, Zuidema J \& Maes RAA 1995 Saliva as an analytical tool in toxicology. International Journal of Drug Testing 1 1-33.

Jordan VC 1983 Laboratory studies to develop general principles for the adjuvant treatment of breast cancer with antiestrogens: problems and potential for future clinical applications. Breast Cancer Research and Treatment 3 (Suppl) S73-S86.

Jordan VC 2001 Selective estrogen receptor modulation: a personal perspective. Cancer Research $615683-5687$.

Jordan VC \& Gosden B 1983 Inhibition of the uterotropic activity of estrogens and antiestrogens by the short acting antiestrogen LY117018. Endocrinology 113 463-468.

Jordan VC, Phelps E \& Lindgren JU 1987a Effects of anti-estrogens on bone in castrated and intact female rats. Breast Cancer Research and Treatment 10 31-35.

Jordan VC, Fritz NF \& Tormey DC $1987 b$ Endocrine effects of adjuvant chemotherapy and long-term tamoxifen administration on node-positive patients with breast cancer. Cancer Research 47 624-630.

Jordan VC, Fritz NF, Langan-Fahey S, Thompson M \& Tormey DC 1991 Alteration of endocrine parameters in premenopausal women with breast cancer during long-term adjuvant therapy with tamoxifen as the single agent. Journal of the National Cancer Institute 83 1488-1491.

Jordan VC, Gapstur S \& Morrow M 2001 Selective estrogen receptor modulation and reduction in risk of breast cancer, osteoporosis and coronary heart disease. Journal of the National Cancer Institute 93 1449-1457.

Lieberman ME, Gorski J \& Jordan VC 1983 An estrogen receptor model to describe the regulation of prolactin synthesis by antiestrogens in vitro. Journal of Biological Chemistry 258 4741-4745.

Lipson SF \& Ellison PT 1992 Normative study of age variation in salivary progesterone profiles. Journal of Biosocial Science 24 233-244.
Lu Y-C, Chatterton RT, Vogelsong KM \& May LK 1997 Direct radioimmunoassay of progesterone in saliva. Journal of Immunoassay 18 149-163.

Lu Y-C, Bentley GR, Gann PH, Hodges KR \& Chatterton RT 1999 Salivary estradiol and progesterone levels in conception and non-conception cycles in women. Evaluation of a new assay for salivary estradiol. Fertility and Sterility 71 863-868.

Partridge WM 1981 Transport of protein-bound hormones into tissues in vivo. Endocrine Reviews 2 103-123.

Powles TJ, Hickish T, Kanis JA, Tidy A \& Ashley S 1996 Effect of tamoxifen on bone mineral density measured by dual-energy X-ray absorptiometry in healthy premenopausal and postmenopausal women. Journal of Clinical Oncology 14 78-84.

Ravdin PM, Fritz NF, Tormey DC \& Jordan VC 1988 Endocrine status of premenopausal node-positive breast cancer patients following adjuvant chemotherapy and long-term tamoxifen. Cancer Research 48 1026-1029.

Read GF, Walker RF, Wilson DW \& Griffiths K 1990 Steroid analysis in saliva for the assessment of endocrine function. Annals of the New York Academy of Sciences 595 260-274.

Sebastian S \& Bulun SE 2001 Genetics of endocrine disease. A highly complex organization of the regulatory region of the human CYP19 (aromatase) gene revealed by the human genome project. Journal of Clinical Endocrinology and Metabolism 86 4600-4602.

Shattuck-Eidens D, Oliphant A, McClure M, McBride C, Gupte J, Rubano T, Pruss D, Tavtigian SV, Teng DH, Adey N et al. 1997 BRCA1 sequence analysis in women at high risk for susceptibility mutations. Risk factor analysis and implications for genetic testing. Journal of the American Medical Association 278 1242-1250.

Snyder KR, Sparano N \& Malinowski JM 2000 Raloxifene hydrochloride. American Journal of Health-System Pharmacy 57 1669-1675 (quiz 1676-1668).

Vogel VG, Costantino JP, Wickerham DL, Cronin WM, Cecchini RS, Atkins JN, Bevers TB, Fehrenbacher L, Pajon ER Jr, Wade JL III et al. 2006 The Study of Tamoxifen and Raloxifene (STAR): report of the national surgical adjuvant breast and bowel project P-2 trial. Journal of the American Medical Association 295 $2727-2741$.

Received 22 August 2006

Received in final form 20 September 2006 Made available online as an Accepted Preprint 2 October 2006 